\title{
Aplicación de las TIC y realidad aumentada como iniciativa para la puesta en valor del patrimonio arquitectónico. Estudios de casos españoles para su posible implementación en contextos patrimoniales costarricenses
}

Application of ICT and augmented reality as an initiative to promote the architectural heritage. Case studies from Spain in order to implementation in Costa Rican heritage contexts

Fernando Agüero-Bravo ${ }^{1}$

Agüero-Bravo, F. Aplicación de las TIC y realidad aumentada como iniciativa para la puesta en valor del patrimonio arquitectónico. Estudios de casos españoles para su posible implementación en contextos patrimoniales costarricenses. Tecnología en Marcha. Vol. 34, especial. Movilidad Estudiantil. Octubre 2021. Pág 62-77.

doi) https://doi.org/10.18845/tm.v34i5.5916 


\title{
Palabras clave
}

Paisaje urbano histórico; patrimonio; Costa Rica; España; turismo; aplicaciones móviles.

\section{Resumen}

La realidad aumentada es una tecnología que ha sido ampliamente desarrollada para fines académicos, educativos y de entretenimiento, algunos países se han valido de esta tecnología para promover la cultura y el turismo urbano en sitios patrimoniales; no obstante, al ser una herramienta con poca exploración en el país, la investigación teórica y aplicada en este campo facilitaría su consolidación en Costa Rica para la puesta en valor del patrimonio arquitectónico.

El presente artículo, a partir de la metodología de estudios de casos, tiene por objetivo evaluar el funcionamiento, propuesta y difusión de aplicaciones móviles que utilizan las TIC para el desarrollo turístico de entornos con interés patrimonial. La evaluación parte de una serie de entrevistas realizadas a expertos de la Universidad Autónoma de Madrid quienes permitieron definir los criterios y posteriormente, se analizaron en campo el funcionamiento de aplicaciones en las ciudades de Segovia, Toledo y Barcelona, ciudades que utilizan estas nuevas tecnologías, para ofrecer, desarrollar y promover su patrimonio cultural. Como principal conclusión, a partir de dicho análisis se elaboró una serie de conclusiones y recomendaciones para su posible implementación en entornos patrimoniales.

\section{Keywords}

Historic urban landscape; heritage; Costa Rica; España; tourism; mobile apps.

\begin{abstract}
Augmented reality is a technology that has been widely developed for academic, educational and entertainment purposes, several countries have used this technology to promote culture and urban tourism in heritage sites; it is a few explored technologies in Costa Rica, thus, theoretical and applied research would facilitate its consolidation in this country in order to promote and develop the architectural heritage.

This article, based on study cases, aims to investigate the operation, proposal and dissemination of mobile applications that use ICT for the tourism development environments with architectonic heritage interest. This study is based on a series of interviews with professionals from Autónoma de Madrid University who allowed defining the criteria and then, analyze the operation of the mobile apps at Segovia, Toledo and Barcelona cities, places that uses these new technologies to offer their cultural heritage. As a main conclusion, from this research was elaborated a series of conclusions and recommendations in order to implement these methods in heritage sites
\end{abstract}

\section{Introducción}

La realidad aumentada es una tecnología que consiste en sobreponer imágenes sobre la realidad mostrada en una pantalla, a través de imágenes, modelos 3D u otro tipo de datos generados previamente por un ordenador [1]. Actualmente, el mercado del consumo de información se enfoca cada vez más hacia los dispositivos móviles, ya sean teléfonos móviles de aplicaciones múltiples (smartphones), tabletas y dispositivos multimedia [2].

Según la referencia [3], dichas herramientas han empezado a cobrar un gran protagonismo y aunado a la rápida implantación de dispositivos multimedia en la sociedad, han propiciado la aparición de nuevos métodos para el tratamiento, interpretación y promoción del patrimonio 
arquitectónico, cultural y del paisaje urbano histórico por medio del uso de herramientas digitales como la realidad aumentada. Es por esto que según diversos autores [4] [1] las aplicaciones móviles orientadas al turismo y la implantación de la realidad aumentada para la puesta en valor del patrimonio arquitectónico pueden convertirse en un nuevo canal que posibilite información, desarrollo y comercialización turística de una forma más eficiente e innovadora.

Tal como se expone en la referencia [5], un sistema de realidad aumentada aplicado al turismo tiene que ser sensible a las preferencias del turista, debiendo establecer mecanismos que permitan recomendarles posibles ofertas relacionadas con sus preferencias e intereses. Las aplicaciones analizadas presentaban la posibilidad de escoger o definir diferentes tipos de itinerarios de acuerdo con las preferencias del usuario, lo que permitía un mayor atractivo y éxito en cuanto uso con la aplicación; además de que otorgan cierta versatilidad para que, en una segunda visita, el usuario tuviera la posibilidad de escoger una nueva ruta.

Dicha tecnología además permite el acceso de información a un amplio sector de la sociedad, ya que muchas de las herramientas que se crean para los usuarios están adaptadas en múltiples idiomas o formas en que personas con alguna discapacidad también pueda aprovechar su uso. Disciplinas como la arqueología, la historia del arte, la arquitectura, han visto en esta tecnología un nuevo recurso para llevar a cabo una labor de difusión y puesta en valor de los entornos patrimoniales, proyectos que han mostrado nuevas perspectivas en la forma de interpretar y conocer el patrimonio [1].

La realidad aumentada recurre al uso de la cámara fotográfica, brújula, receptor GPS y otros implementos presentes en los dispositivos móviles para cargar imágenes, información o animaciones previamente realizadas en computadora. Por ejemplo, España a través de la realidad aumentada, ha sabido aprovechar estas tecnologías, para poner a disposición su patrimonio cultural y arquitectónico, generando una visión indirecta del entorno real por medio de elementos virtuales visibles en una pantalla de un dispositivo móvil [1] [5]. .

En el caso de Costa Rica, dicha tecnología se ha utilizado en el ámbito educativo para presentar, por medio de dispositivos móviles, recursos educativos y mostrar de una manera más didáctica contenidos y temas impartidos en clases escolares en el ámbito de las ciencias, estudios sociales e idiomas dirigido tanto a estudiantes como a educadores [6] [7].

También se ha centrado su uso en el ámbito publicitario para mostrar de una manera diferente, creativa y original los productos comercializados y materiales promocionales[8] [9]. Asimismo, se han establecido iniciativas privadas que han aprovechado la realidad aumentada para generar videojuegos y su posible implementación en el mercado de la ingeniería y mercadeo, finalmente, se ha aprovechado de esta herramienta para promocionar el turismo en edificios emblemáticos como el Teatro Nacional de Costa Rica, el cual, por medio de una aplicación de realidad aumentada, dio a conocer el arte y las reliquias presenten en este lugar [10] [11].

No obstante, desarrollo de tecnologías para la puesta en valor de edificios patrimoniales o paisajes urbanos históricos, ha sido un ámbito muy poco explorado y demanda de un sustento teórico que permita seguir avanzando para su implementación en esta área; se encontró como única y primera aplicación de realidad aumentada para la puesta en valor y difusión del paisaje urbano histórico de barrio Amón, la aplicación Amón_RA, proyecto financiado por la vicerrectoría de Investigación y Extensión del TEC, en el cual participan las Escuelas de Arquitectura y Urbanismo, Computación y Diseño Industrial del TEC que pone en valor el paisaje urbano histórico de barrio Amón en San José, como una forma de ver viable a futuro la expansión de estos proyectos en otros entornos patrimoniales [12]. 
Una de las grandes ventajas que posee la realidad aumentada sobre las otras maneras de promoción del patrimonio arquitectónico es que, a través de esta tecnología, se puede mostrar información al turista o público en general de edificaciones o monumentos que desaparecieron o se encuentran parcialmente destruidos; según Caro, J. et al [5], permite presentar una recreación virtual de elementos con acceso restringido o parcialmente destruidos y con ello poner en valor obras arquitectónicas que, debido a su estado físico, pierden su valor y trascendencia la sociedad.

A manera de ejemplo, una edificación patrimonial en Costa Rica el cual sería viable una iniciativa para la implementación de la realidad aumentada como herramienta para su rescate y conservación de la memoria cultural es el templo Santiago Apóstol, dicha herramienta permitiría observar su interior, revelar su historia y su trascendencia en la cultura de los habitantes de Puriscal.

Según Tato, B. y Vallejo, J. [13], en la esfera urbana, estas iniciativas contemporáneas que incorporan al ciudadano como agente activo, huyendo del paradigma convencional del ciudadano cliente-espectador-receptor permite pasar al ciudadano a ser actor-productor en un proceso abierto de la dinámica de una ciudad. La incorporación de las TIC y de tecnologías como la realidad aumentada empezarán a crear un espacio aumentado susceptible a ser modificado o ajustado a las necesidades que se requieran, dichos recursos lograrán un mayor entendimiento del espacio urbano y patrimonial existente y proveerá la información necesaria para que el usuario local o turista pueda hacer libre uso de este espacio, lo que definirá nuevas formas de interacción y de entender el entorno.

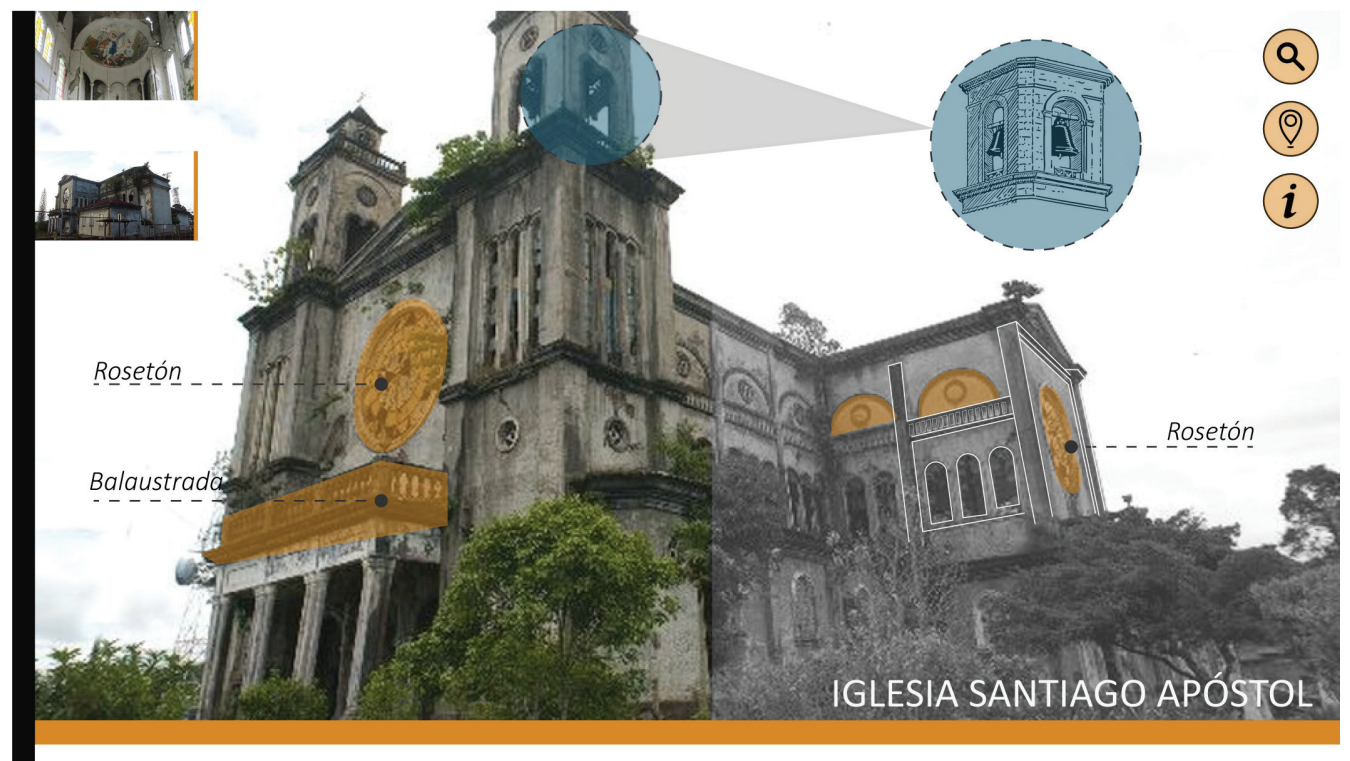

Figura 1. Visualización de una posible propuesta realizada por el autor de implementación de realidad aumentada en una edificación patrimonial costarricense. Datos, diagramas y comparación de distintas épocas de la Iglesia Santiago Apóstol. Fuente de la imagen: La Nación

\section{Materiales y métodos}

El Programa de Movilidad Estudiantil, con fondos del sistema CONARE, permitió la visita para el desarrollo de estudios de casos a través de entrevistas y trabajo de campo en Segovia, Barcelona y Toledo, ciudades españolas que cuentan con una amplia experiencia en la 
implementación de las TIC en el sector turístico-cultural y el uso de aplicaciones móviles con realidad aumentada. Asimismo, experimentar la interfaz de las aplicaciones móviles y la manera en cómo se difunden, permitió obtener un mejor entendimiento de la puesta en valor del patrimonio arquitectónico, además de elaborar nueva documentación y referencias necesarias para continuar ampliando este modelo en entornos patrimoniales costarricenses

Como parte de la metodología de la investigación, se contó con el apoyo de expertos de la Universidad Autónoma de Madrid, especialistas en geografía humana y amplia experiencia en el sector turístico apoyado por las TIC; esto con el fin recolectar información precisa para conocer la realidad del uso de estas tecnologías en España y conocer la experiencia profesional en cuanto a la utilización de la realidad aumentada para la puesta en valor de entornos patrimoniales con alto interés cultural. Tal como se expone en la imagen 2, para cada una de las entrevistas realizadas, se confecciono una guía de preguntas enfocada al ámbito laboral y profesional del entrevistado, con el fin de obtener los datos pertinentes para lograr una metodología de análisis más integral al momento de realizar el estudio de casos de las ciudades previamente seleccionadas.

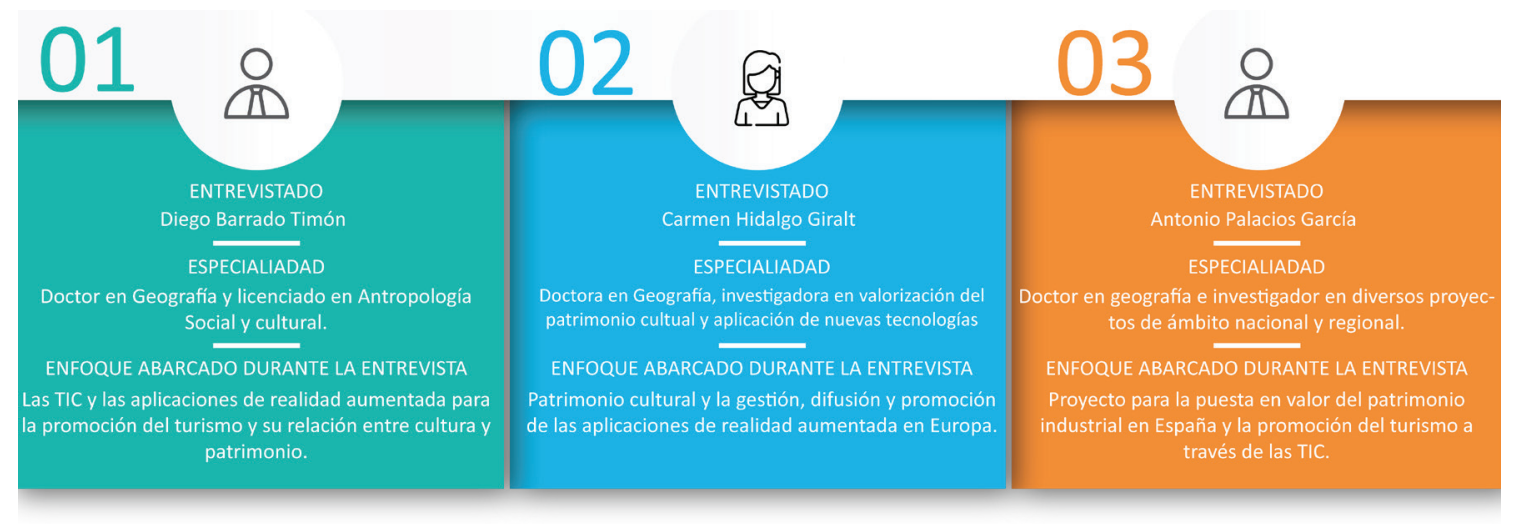

Figura 2. Tabla de datos de los entrevistados con los distintos enfoques abarcados durante las entrevistas.

De la misma manera, parte de la metodología implementada fue la realización estudios de caso de ciudades que implementaban las TIC y la realidad aumentada en las ciudades de Toledo, Segovia y Barcelona para conocer la incidencia, la implementación y la difusión de estas tecnologías en entornos altamente turísticos, con declaratoria de patrimonio de la humanidad según la UNESCO y con gran valor en su arquitectura y el paisaje urbano.

Se analizaron las propuestas para aplicaciones móviles que ponían en valor el patrimonio arquitectónico y cultural de la zona y que por medio de las TIC promocionaban el turismo. En la figura 3 se observan los distintos parámetros y criterios utilizados para evaluar las aplicaciones en cada una de las ciudades a través de observación participante, la cual es una herramienta que permite la recolección de datos cualitativos del fenómeno estudiado y permite un mejor entendimiento de los fenómenos estudiados [14]. 


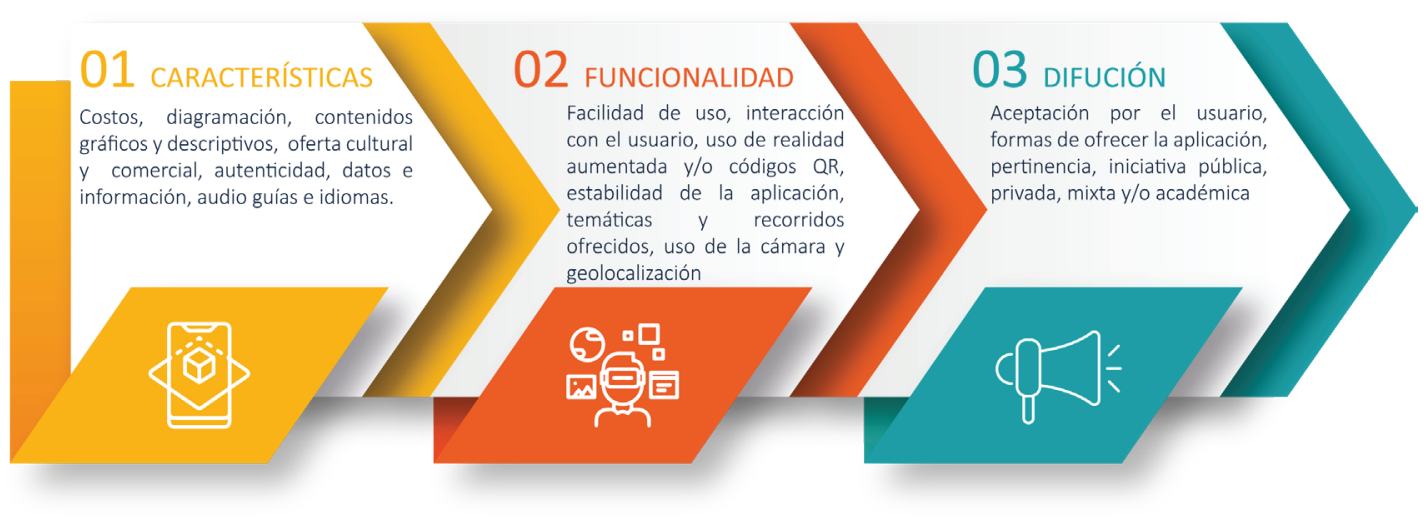

Figura 3. Categorización de parámetros para el análisis de aplicaciones de realidad aumentada y promoción del turismo por medio de las TIC,para cada uno de los estudios de casos.

\section{Resultados}

Las distintas entrevistas realizadas, permitieron conocer la realidad y la forma en cómo se implementan las TIC y la realidad aumentada en el sector turístico para la puesta en valor del patrimonio cultural en España. La relación entre los distintos enfoques planteados para las entrevistas y los distintos campos multidisciplinares de los expertos, permitió obtener los siguientes resultados, premisas base para el posterior análisis de cada uno de los estudios de caso:

Inicialmente, según Palacios [15], el acelerado avance tecnológico de los últimos años hace que se deba repensar y gestionar de una manera diferente la manera en que se promociona el turismo, además, este debe de vincular el uso de las tecnologías de la información. El turismo es considerado como una de las actividades económicas más importantes de una ciudad, sino expresamente como una de las "actividades de futuro" en el marco de la "nueva economía". Su experiencia en la puesta en valor del patrimonio industrial, le permite afirmar la importancia de las nuevas tecnologías en sitios con potencial turístico y como ellas logran vincular de una manera mas eficiente e interactiva el usuario con la ciudad.

Asimismo, según Hidalgo y Barrado [16] [17], la realidad aumentada y la promoción de las TIC en el turismo son herramientas muy eficaces para potenciar y dar a conocer el patrimonio arquitectónico y cultural de una región; además, su vinculación permite revalorizar edificaciones o monumentos que han perdido su valor en la memoria colectiva de una sociedad

La promoción de las TIC y de tecnologías como la realidad aumentada permite una mayor participación de los usuarios en la ciudad o su contexto y el refuerzo del conocimiento del patrimonio perdido o parcialmente conservado. Asimismo, traen consigo dos efectos particularmente beneficiosos para la protección del patrimonio y la "conciencia cultural" y "conciencia del patrimonio" y es que promueven la sensibilidad de los usuarios al patrimonio y la cultura, y aumentan la participación tanto en las ciudades como en los museos [16] [17].

Estas tecnologías permiten enriquecer la experiencia turística, añadiendo información al entorno real fusionada con la pantalla de un dispositivo. La realidad virtual y la realidad aumentada permiten a la ciudad o aun pequeño territorio asumir el rol de un "museo abierto" y las nuevas tecnologías dentro del contexto del smart city pueden ser usadas cada vez más para el turismo, la cultura y la investigación. En este contexto de cambio social y cultural en el consumo turístico, la realidad aumentada da lugar a crear contenido más inmersivo que aumenta la satisfacción del usuario [16] [17] [18]. 
Según Hidalgo [16] entre las limitantes encontradas con el uso de esta tecnología se halla la incapacidad del visitante de balancear la información dada por la aplicación, y el contexto real, centrándose únicamente en la experiencia virtual y no en el contexto físico y según Barrado [17] la idea de la realidad amentada está mejor dirigida a sitios no tan conocidos turísticamente, ya que al ser una herramienta innovadora presenta mayor ventajas en la atracción de turismo en zonas más desconocidas y con afluencia turística menor que en ciudades donde el hecho de ser patrimonio de la humanidad, ya presentaban una oferta y atracción turística bastante alta.

Dichas entrevistas permitieron generar una concepción previa al momento de evaluar el funcionamiento, propuesta y difusión de aplicaciones móviles que utilizan las TIC y la realidad aumentada para el desarrollo turístico en entornos con interés patrimonial, por lo que los insumos teóricos generados en esa metodología, permitieron el estudio crítico de tres ciudades, con obras y contextos declarados patrimonio de la humanidad que implementan estas tecnologías para revalorizar el patrimonio cultural, arquitectónico y el paisaje urbano histórico.

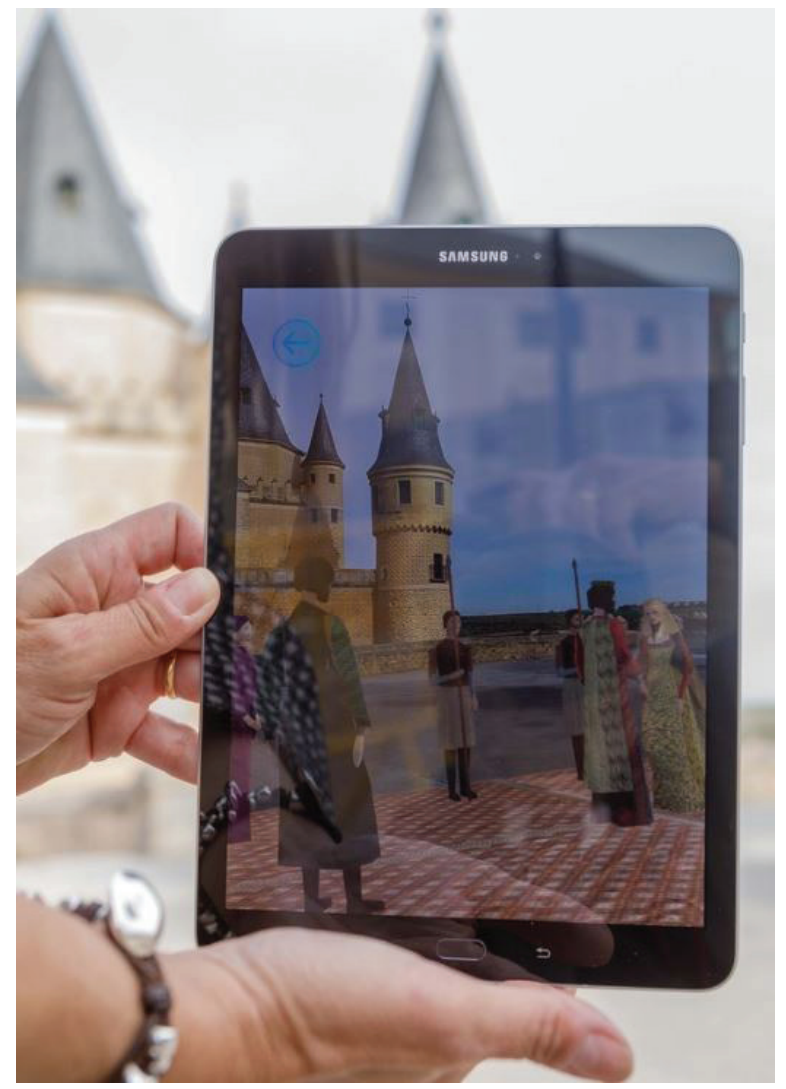

Figura 4. Realidad aumentada aplicada al Alcázar de Segovia. Fuente: eldíasegovia.es

La primera ciudad analizada fue Segovia, declarada Patrimonio de la Humanidad por la UNESCO en 1985, es un foco de recepción de turistas de primer orden a nivel nacional e internacional, por su rico y variado patrimonio histórico-artístico [19].

Dicha ciudad ha desarrollado en los últimos años diversos proyectos en materia de turismo arquitectónico, cultural y según diversas investigaciones [19] [20], ha implementado el desarrollo de aplicaciones en realidad aumentada (imagen 4), proyectos abordados por iniciativas públicas por parte del ayuntamiento y del estado, así como el apoyo de diversos colectivos ciudadanos. 
En el caso de Segovia, el impacto de las TIC y la realidad aumentada está enfocado a dar conocer su turismo y grandes atractivos arquitectónicos de la ciudad. Por medio de aplicaciones móviles y sitios web, el ayuntamiento de Segovia ha logrado poner en valor las obras y edificaciones de interés turístico y cultural por medio de códigos QR, esto con el fin de dar a conocer la historia e interés cultural de cada una de ellas. En la imagen 5, se observa una publicidad con información básica del elemento arquitectónico, pero a su vez el código que enlaza a la página web del ayuntamiento, así como de la aplicación para dispositivos móviles que le permitirá seguir una ruta turística.

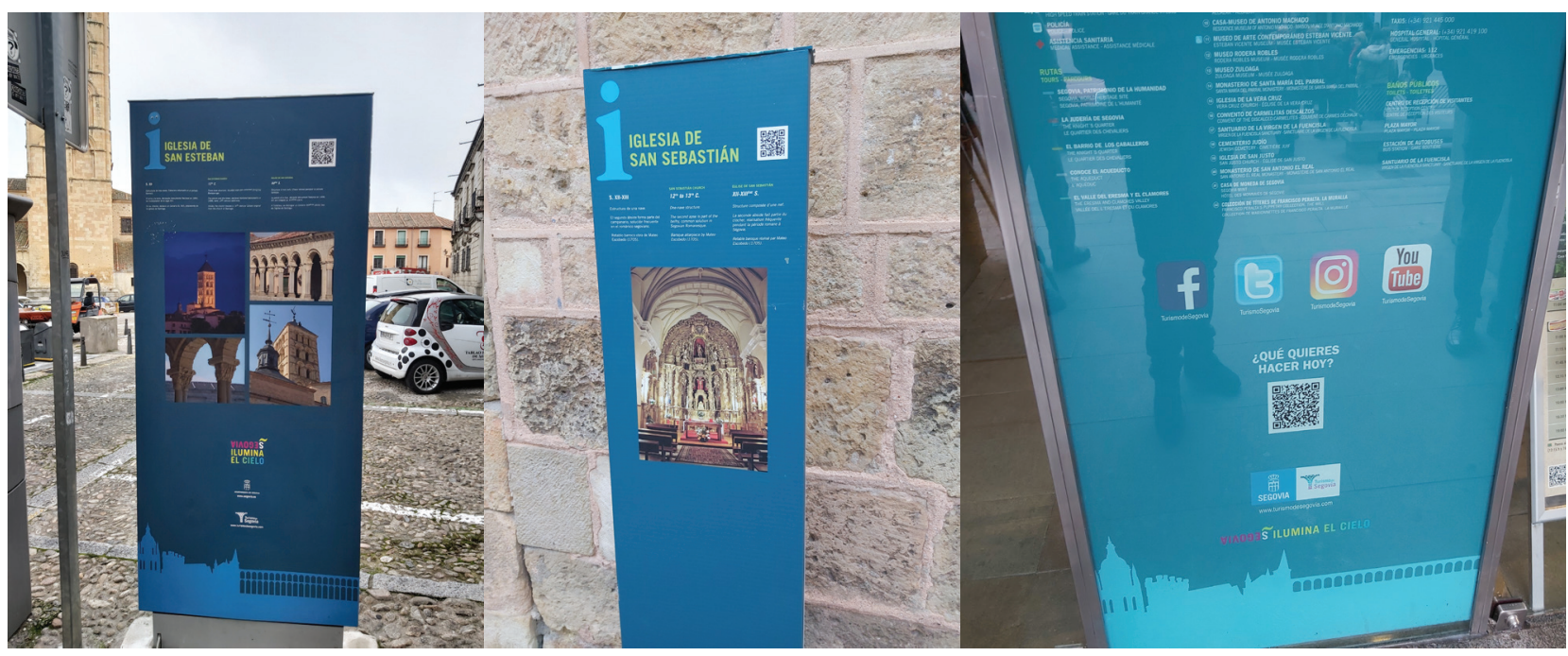

Figura 5. Información y códigos QR en las afueras de cada obra arquitectónica con interés patrimonial.

De la misma manera, muchos museos y edificios poseen aplicaciones propias que permiten al usuario vivir una experiencia más enriquecedora de los sitios donde se encuentren, así como datos de los atractivos turísticos de la obra en su interior. En la imagen 6, se observa la publicidad a la entrada del museo de la Catedral de Segovia con un código para la descarga de una aplicación que permitirá entender las obras artísticas a mayor profundidad.

Las aplicaciones móviles en esta ciudad se difunden por medio de folletos turísticos, puntos de información turística y puntos estratégicos de la ciudad (imagen 7), páginas web, noticias y la página oficial de turismo en Segovia; asimismo, en la entrada de cada obra arquitectónica con interés patrimonial o histórico y museos hay letreros con la información correspondiente a la aplicación o página web que proveerá de la información pertinente para cada sitio.

Según Arribas et al [2], para el desarrollo de las actividades turísticas en Segovia se han propuesto infinidad de materiales interpretativos y recursos, desde los clásicos paneles y posters, a las audioguías, pasando por los clásicos folletos, guías y manuales impresos. La irrupción de las tecnologías de la información y de la comunicación (TIC) hace necesario introducir estas herramientas que ponen aún más el valor el patrimonio existente; además de potenciar las posibilidades y la difusión del objeto cultural [21]. 


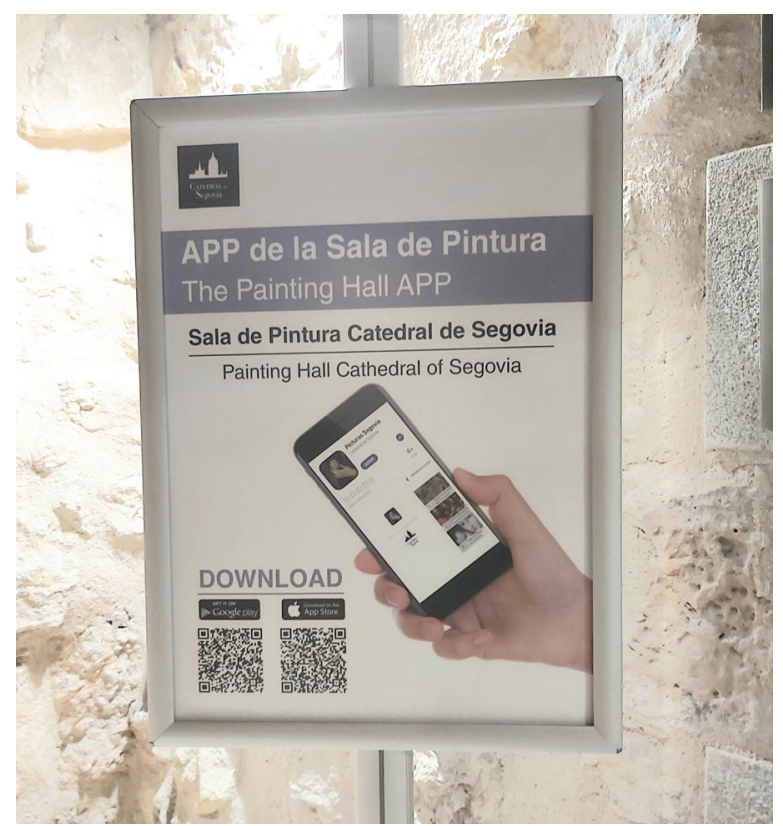

Figura 6. Promoción de aplicaciones móviles, Catedral de Segovia.

Como segunda ciudad analizada, se procedió a estudiar la implementación de estas tecnologías en la ciudad de Barcelona, principalmente en los sectores con mayor número de edificaciones de carácter patrimonial. Según el Ayuntamiento de Barcelona [22] el turismo es una de las actividades más importantes de Barcelona y representa una prioridad, tanto por la aportación que representa para la economía de la ciudad como por los diversos efectos que genera en la dinámica urbana. La alta cantidad de monumentos, edificios y barrios históricos que componen la ciudad de Barcelona y el aumento en la movilidad la han convertido en una ciudad turística en tiempo récord y probablemente seguirá siéndolo en un futuro próximo.
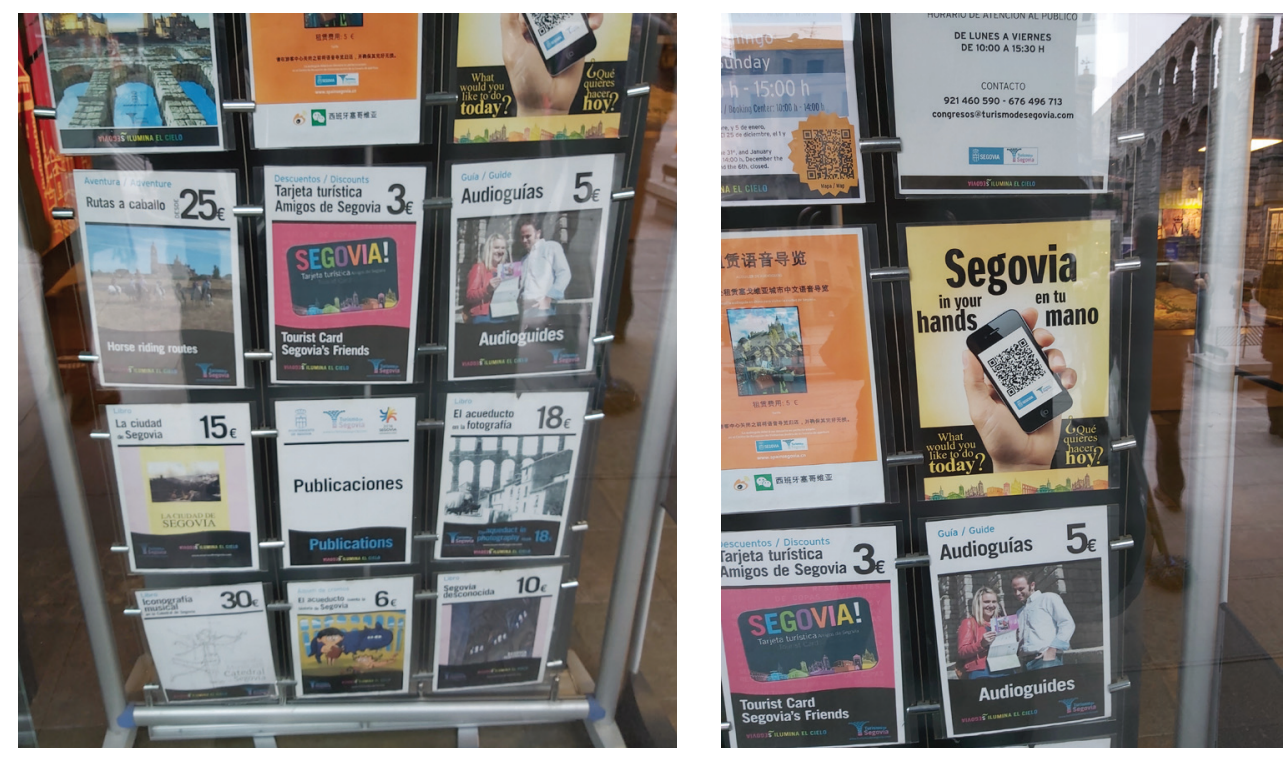

Figura 7. Publicidad de las aplicaciones móviles a las afueras de puestos de información turística.

"Podemos decir que Cataluña está a la vanguardia de la aplicación de tecnologías TIC en el ámbito turístico, las nuevas tecnologías han permitido pasar de un producto turístico homogéneo a un producto individual para cada segmento de visitantes" [23]. 
Es por lo anterior que Barcelona ha apostado por la creación y difusión de aplicaciones que permiten explotar su turismo por medio de la puesta en valor de su arquitectura. Tanto iniciativas privadas como públicas se han dado la tarea de crear aplicaciones que utilizan la realidad aumentada para dar a conocer lo más relevante del contexto urbano de la ciudad y de las diferentes edificaciones y monumentos que componen la región (figura 8).

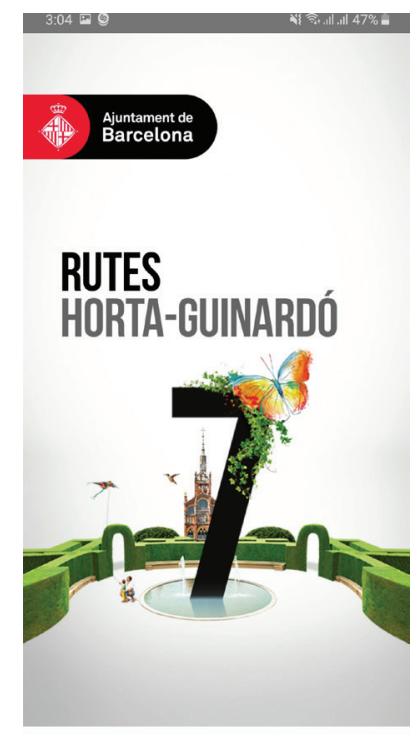

Pulsar aqui para abarcar la pantalla completa

Figura 8. Aplicación Rutes Horta-Guinardo.

Entre la iniciativa pública, existen múltiples aplicaciones como: Ciutat Vella, Gracia, HortaGuinardo, Nou Barris Rutes Sant Andreu, Sarriá-Sant Gervasi, etc que ofrecen información relevante tanto a turistas como habitantes de la zona para poner en valor el patrimonio histórico y cultural. Dichas aplicaciones, ofrecen rutas turísticas en distintos idiomas, lo que la hacen bastante accesibles la mayoría de los turistas y la forma en que está diseñada la interfaz, las convierten en herramientas intuitivas sencillas de utilizar.

Según diversas fuentes [22] [23], la alta cantidad de turismo que recibe Barcelona año a año ha permitido la posibilidad de proponer aplicaciones que le ofrecen al usuario realizar con un dispositivo móvil rutas preestablecidas en diferentes puntos de la ciudad; el usuario puede escoger la ruta de su preferencia y cada una de ellas utilizará información histórica, imágenes, audioguías y mapas para crear un recorrido dinámico para el usuario; asimismo, estas aplicaciones utilizan la realidad aumentada para generar un contenido visual más interactivo y con la pantalla del dispositivo ir mostrando en tiempo real el nombre del sitio en donde se encuentra o el nombre de la edificación o monumento al que está apuntando la cámara del dispositivo. 


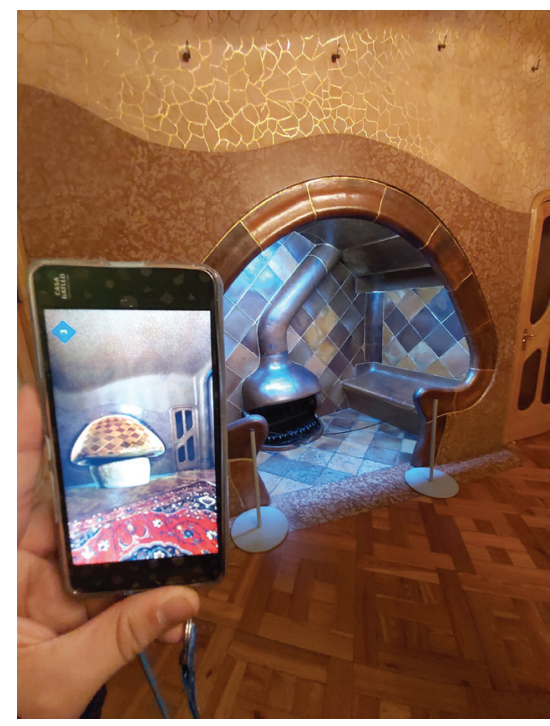

Figura 9. Dispositivo que utiliza realidad aumentada en el interior de la Casa Batlló, Barcelona.

Dichas iniciativas además proveen de información relevante de la zona donde se encuentra y un video explicativo que muestra información general del lugar; asimismo, muestran listados de diferentes hitos de la ciudad, cada uno de ellos con información pertinente para conocer de su trascendencia histórica y cultual y un mapa que muestra la ubicación de cada uno de los sitios. Las aplicaciones ofrecen el uso de la realidad aumentada en cada una de las rutas que se escoja y dicha herramienta permite generar una experiencia distinta a lo ofrecido comúnmente en otras atracciones turísticas en ciudades con gran valor patrimonial y cultural. La gran mayoría de las aplicaciones no dependen de una conexión a internet permanente para ser utilizadas, con excepción de algunos videos o imágenes que si requieren una conexión para su visualización.

Asimismo, se pone a disposición aplicaciones que vinculan las tecnologías de la información como Barcelona y Visit Barcelona; aplicaciones de acceso gratuito que no utilizan realidad aumentada, pero ofrecen la información suficiente y actualizada de la ciudad como mapas, zonas de interés, oferta cultural, ocio, comercio, gastronomía y alojamiento, también de información acerca del clima, transporte, itinerarios, tours y noticias recientes de la ciudad.

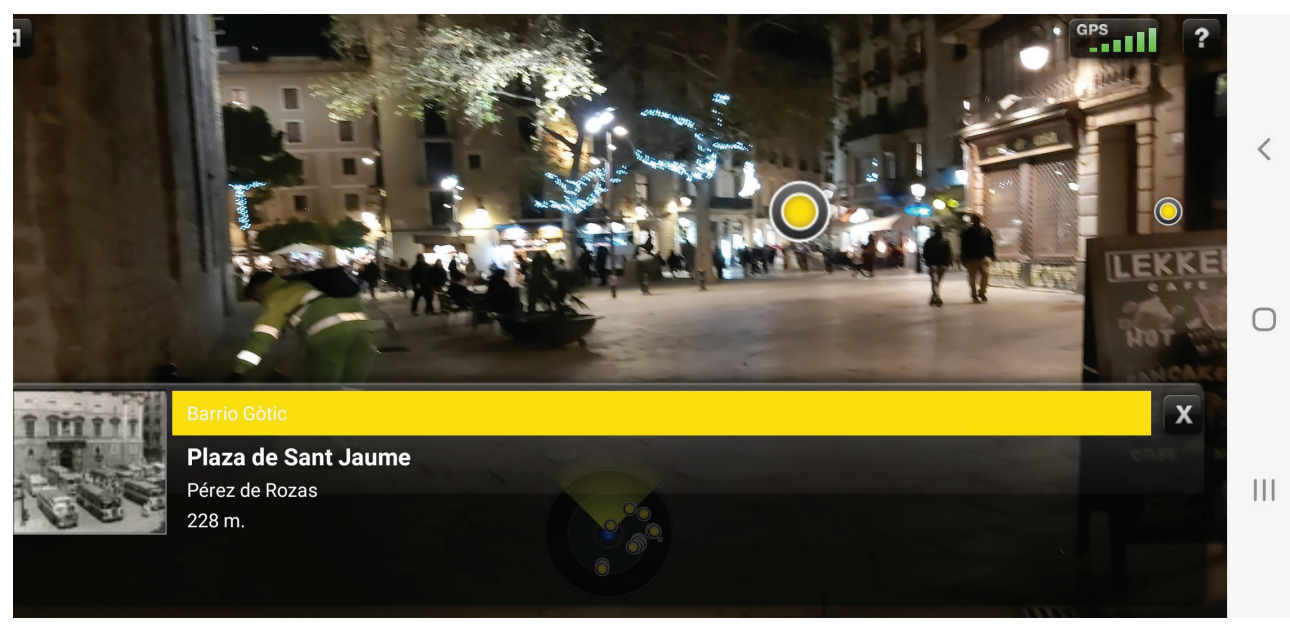

Figura 10. Aplicación de la realidad aumentada en contexto urbano. 
La gran cantidad de alternativas que el Ayuntamiento de Barcelona ofrece, hace que sea uno de los mejores ejemplos de promoción del patrimonio cultural y arquitectónico de las ciudades analizadas. Asimismo, el hecho de que sean gratuitas y la interfaz accesible para cualquier usuario, aseguran en gran parte el éxito de las aplicaciones.

No obstante, por medio de observación participante y no participante no se logró validar su uso por otros locales y/o turistas; de la misma manera, en los puntos de información turística carecían de la información necesaria para descargar las aplicaciones, en contraste con la ciudad de Segovia que la manera de difundir y promocionar las aplicaciones era más apropiada, dicho inconveniente limitaba la interacción por medio de estas aplicaciones en la ciudad, eran herramientas desconocidas por la gran mayoría de la población y por ende les hacía perder el valor y el gran potencial existente en dichas propuestas.

Finalmente; se estudió las distintas propuestas para la promoción del turismo en la ciudad de Toledo, sitio que data del siglo IV antes de Cristo, su historia, su arquitectura y las culturas que han conformado lo que hoy es la han convertido en Ciudad Patrimonio de la Humanidad. Toledo se ha destacado por que en los últimos años se ha sabido aprovechar las nuevas tecnologías de la información y junto con la realidad aumentada ha logrado promocionar y dar a conocer sus atractivos turísticos y culturales de la zona.

Según Palacios [15] las ciudades donde su mayor fuente de ingresos y sustento económico es el turismo, este debe de explotarse y plantear las herramientas necesarias adecuadas a la época para darse a conocer y seguir manteniendo su gran atractivo en el tiempo. Es por lo que la ciudad de Toledo ha puesto en marcha el proyecto Toledo Ciudad Inteligente, _iniciativa pública que adoptó el Ayuntamiento para ofrecer una nueva forma de descubrir el ambiente urbano y visualizar la realidad de una forma distinta ofrecida por teléfonos inteligentes [24].

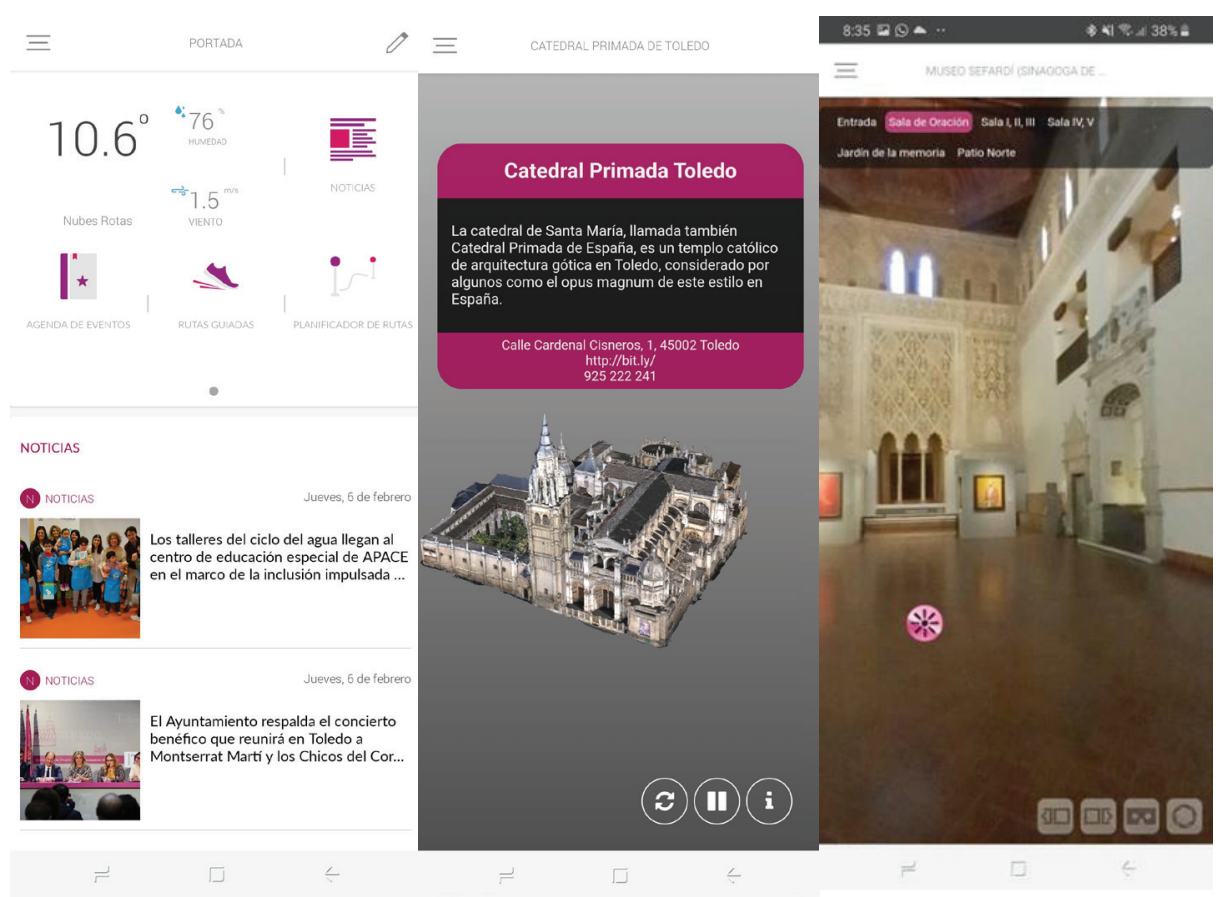

Figura 11. Menú principal, visualización de modelos 3D y realidad aumentada en edificaciones patrimoniales de la aplicación Cintoledo. 
Tal como lo indica la referencia [24] Cintoledo es un proyecto que se ha desarrollado siguiendo dos líneas de actuación; por una parte, aplicaciones y servicios para los vecinos de Toledo y los turistas y, por otra parte, herramientas para mejorar la gestión de la ciudad y facilitar los procesos de toma de las decisiones. Toledo además ha realizado las gestiones necesarias para mantener la conexión de red inalámbrica en gran parte de la ciudad, esto como un plan para asegurar el éxito de la aplicación. La aplicación ofrece locuciones por parte de personajes históricos, que muestran los principales atractivos que la ciudad tiene que ofrecer, rutas para hacer turismo urbano y de una manera didáctica e interactiva promover la cultura de la ciudad; de la misma manera, la aplicación pone a disposición modelos digitales de las principales obras de arquitectura y la oferta comercial, lo que permite a los visitantes vivir una experiencia distinta e innovadora durante su recorrido.

La aplicación municipal dispone del canal smart en el cual los ciudadanos pueden comunicarse con el Ayuntamiento para transmitir incidencias que detecten en la prestación de servicios municipales y, además, proporciona información de interés para los usuarios e incluso les permite participar en los plenos municipales enviando sus opiniones o preguntas al equipo de Gobierno [25].

\section{Recomendaciones}

Las ciudades o pueblos cuya economía dependa en gran parte del turismo deben de apostar por alternativas que vinculen las TIC con el turismo, o con formas más innovadoras como la realidad aumentada para dar a conocer su oferta patrimonial y cultural de un manera más ágil, eficiente e interactiva para los usuarios tal como se observó en las ciudades de Segovia, Barcelona y Toledo.

Las universidades deben de seguir apoyando e impulsando proyectos de esta índole que, además de dar a conocer el patrimonio arquitectónico y cultural de una zona, permite sensibilizar a las personas con la historia y la identidad que cada lugar de estos posee, además, daría a conocer la oferta turística local y beneficiar el comercio que existe en estas comunidades.

En relación con las aplicaciones móviles, se debe de tener presente el mantenimiento de la aplicación una vez que esta ha sido publicada, asimismo, se debe de prever un periodo de mejoras, modificaciones y actualizaciones que surgirán una vez haya sido lanzada la aplicación al mercado.

Es necesario que exista un nivel adecuado de conectividad a datos móviles o internet inalámbrica en estos entornos, esto permitirá un correcto funcionamiento de la aplicación. Se debe de realizar las gestiones o ajustes necesarios que permitan que la aplicación funcione correctamente en el lugar destinado para su aplicación.

Tal como se hizo en Segovia, la forma de difundir la información debe de ser la adecuada para que todos los ciudadanos y turistas puedan tener acceso a la aplicación, los puntos de información turística, letreros con códigos QR, publicación en páginas web y publicaciones digitales son algunos ejemplos de técnicas que utilizó este lugar para promocionar su patrimonio arquitectónico

Las aplicaciones que se vayan a proponer para este fin, deben ofrecer una interfaz de uso sencilla; pero a su vez debe de ofrecer diversidad de contenido actualizado que permita ser una herramienta funcional para el usuario y no caer en desuso; de la misma manera, debe de existir algún tipo de interacción entre la aplicación y el usuario más allá de proveer información, en los casos estudiados los juegos virtuales, la capacidad de dejar una opinión, conocer la oferta cultural y comercial de la zona, son ejemplos que las aplicaciones utilizaban para asegurar su éxito y continuidad en el mercado. 


\section{Conclusiones}

A manera de conclusión de los casos de estudio anteriormente presentados, Segovia es una de las ciudades que más invierte en la promoción de sus bienes patrimoniales vinculando las TIC para dar a conocer el turismo en la región y ofrecer alternativas más innovadoras a sus visitantes. Los métodos ofrecidos no tienen costo alguno, muestran un interfaz sencillo de utilizar, su uso es aceptado y utilizado por la población y turistas que visitan dicha ciudad y la gran mayoría de ellas son creadas y ofrecidas por parte de iniciativas públicas.

Por otra parte, Barcelona entre las ciudades en estudio, es una de las ciudades que mejor ha logrado vincular el desarrollo de las TIC y las nuevas tecnologías para poner en valor su patrimonio, cultura y arquitectura; las diferentes interfaces aplicadas en cada uno de los softwares para dispositivos móviles eran sencillos y proveían de la información necesaria para conocer de la mejor manera cada parte de la ciudad. Lo relevante de estas aplicaciones es que la gran mayoría son gestionadas por parte de iniciativas públicas y todas ellas tienen como principal objetivo promocionar el turismo por medio de nuevas tecnologías sin ningún fin de lucro.

Tal como se describió en los resultados, Toledo es una ciudad que logró satisfactoriamente generar una aplicación atractiva para la promoción de su turismo; sin embargo, la falta de promoción y difusión de la aplicación generaba que los visitantes usaran folletos y guías de viaje impresas para recorrer la ciudad.

Se ha podido corroborar la importancia de la realidad aumentada durante la última década y su trascendencia en el campo patrimonial y la promoción de las TIC en las ciudades analizadas. Estas herramientas permiten mostrar elementos del pasado que han desaparecido, información adicional invisible a simple vista, además de ser herramientas interactivas y educativas que enriquecen la experiencia turística de un lugar.

La mayoría de las aplicaciones citadas, cumplen una labor didáctica y lúdica, ideal en los entornos culturales, mientras que por otra es posible la difusión de los estudios e investigaciones que quedarían dentro de un marco estrictamente académico.

Entre los principales inconvenientes encontrados en las aplicaciones de realidad aumentada en el turismo, es que habitualmente muestran a los usuarios un número muy elevado de puntos de interés; lo que genera una dificultad para acceder a la información deseada, más cuando este aún no domina o se le dificulta el uso de esta tecnología, por tanto, cuando se plantea, diseña y ejecuta una aplicación con este fin turístico debe de establecerse un contenido específico o una estrategia para que los resultados ofrecidos al usuario sean los adecuados.

En cuanto al funcionamiento de las aplicaciones, aún la tecnología no es capaz de dar solución a problemas gráficos que genera el uso de la realidad aumentada, en muchos casos el resultado no es realista y los edificios existentes ocultan parte o todo el modelo 3D. Una de las maneras que se utiliza para mantener la homogeneidad y estabilidad de la visualización en realidad aumentada es el modelado 3D del contexto inmediato y del objeto arquitectónico para conseguir ese valor de realismo en las aplicaciones y lograr vincular la realidad y la experiencia con la tecnología o elementos virtuales que complementan la visita.

De igual manera, la falta de promoción y difusión de estas herramientas digitales constituye como el principal inconveniente encontrado en los tres casos estudiados, se debe de plantear las estrategias pertinentes para dar a conocer estas herramientas tecnológicas si se desea incluir las TIC en el ámbito turístico de una manera más efectiva. 
Este tipo de propuesta cambia la manera en cómo la información es construida y difundida, la incorporación del ciudadano en el proceso creativo y tecnológico que está empezando a surgir, lleva consigo beneficios directos, entre ellos: facilita el desarrollo, aumenta la aceptación y entendimiento del entorno y al igual que los autores Tato, B. y Vallejo, J. [13] permite amplificar y estimular la oferta cultural relacionada con la arquitectura y la ciudad, logrando de esta manera llegar a un público más amplio y diverso.

Las TIC aplicadas al turismo permiten descubrir cosas nuevas y crear nuevas relaciones, estos enlaces proponen una nueva estructura intelectual basada en un sistema de redes y relaciones que favorecen las dinámicas de interacción social lúdicas para vivir la ciudad, como en los casos analizados de Segovia, Barcelona y Toledo.

\section{Agradecimientos}

Esta publicación se llevó a cabo gracias a la Convocatoria de Fondos para Movilidad Estudiantil de CONARE, con el apoyo del Proyecto Amón_RA del Instituto Tecnológico de Costa Rica, la Escuela de Arquitectura y Urbanismo del ITCR e investigadores de la Universidad Autónoma de Madrid.

\section{Referencias}

[1] C. Prendes Espinoza, "Realidad aumentada y educación: análisis de experiencias prácticas," no. 46, pp. 187-203, 2014, doi: 10.12795/pixelbit.2015.i46.12.

[2] A. Arribas. A. Díez-Herrero, I. Gutiérrez-Pérez, and J. Vegas. "Desarrollo de un filtro de realidad aumentada para telefonía móvil sobre el patrimonio geológico de la provincia de Segovia.”. pp. 21-28, 2013.

[3] J. L. Leiva-Olivencia, "Realidad aumentada bajo tecnología móvil basada en el contexto aplicada a destinos turísticos," 2014.

[4] J. L. L. Olivencia, A. G. Plaza, and C. R. Jiménez, "Sistemas de recomendación para realidad aumentada en un sistema integral de gestión de destinos," vol. 0, no. 14, pp. 69-81, 2012.

[5] J. L. Caro, A. Luque, and B. Zayas. "Nuevas tecnologías para la interpretación y promoción de los recursos turísticos culturales," PASOS. Revista De Turismo Y Patrimonio Cultural, vol.13, no.4, pp. 931-945, 2015. Available: https://www.redalyc.org/articulo.oa?id=88140288014

[6] MEP, "Flora and Fauna in Costa Rica | Ministerio de Educación Pública, 2018. [Online]. Available: https://www. mep.go.cr/educatico/flora-and-fauna-costa-rica. [Accessed: 2020]

[7] MEP, “¿Qué hay de nuevo en Educatico?| Ministerio de Educación Pública,” 2018. [Online]. Available: https:/l www.mep.go.cr/educatico/nuevo-educatico. [Accessed: 2020]

[8] W. Montes, "Tecnología y emprendimiento: WOW Emotions," 2018. [Online]. Available: https://www.larepublica.net/noticia/tecnologia-y-emprendimiento-wow-emotions. [Accessed: 25-Mar-2020]

[9] "La Realidad Aumentada en Costa Rica," 2019. [Online]. Available: http://smartechgroup.es/la-realidadaumentada-en-costa-rica/. [Accessed: 25-Mar-2020]

[10] ITNow, "Startup tica, pionera en realidad aumentada," 2017. [Online]. Available: https://revistaitnow.com/ startup-tica-pionera-realidad-aumentadal. [Accessed: 25-Mar-2020]

[11] M. Vargas, "Realidad aumentada hace accesibles reliquias del Teatro Nacional," 2017. [Online]. Available: https://www.nacion.com/tecnologia/moviles/realidad-aumentada-hace-accesibles-reliquias-del/ AHHHIVQ5UBG5JPIXVV4LJHBVKM/story/. [Accessed: 26-Mar-2020]

[12] D. Porras and E. Solano, "La implementación de la realidad aumentada como valor agregado para la puesta en valor y difusión del paisaje urbano histórico," pp. 147-156, 2019.

[13] B. Tato and J. Villejas, "Escenarios urbanos," p. 21, 2011.

[14] E. P. Aguiar, "Observación participante: una introducción.," pp. 80-89, 2015.

[15] A. Palacios (private communication), 2019.

[16] C. Hidalgo. (private communication), 2019. 
[17] D. Barrado (private communication), 2019.

[18] D. A. Barrado-Timón and C. Hidalgo-Giralt, "The Historic City, Its Transmission and Perception via Augmented Reality and Virtual Reality and the Use of the Past as a Resource for the Present: A New Era for Urban Cultural Heritage and Tourism," vol. 11, no. 10, p. 2835, May 2019, doi: 10.3390/su11102835.

[19] D. M. Sastre, I. R. Martín, and L. R. Martín, "La experiencia 5G en el turismo: el caso de Segovia, Ciudad Patrimonio de la Humanidad," no. E24, pp. 336-348, 2019.

[20] "La realidad aumentada llega al Alcázar," 2019. [Online]. Available: https://www.eldiasegovia.es/noticia/ ZB658E632-EB1A-8E3E-81102DD0874B0E55/201905/la-realidad-aumentada-llega-al-alcazar. [Accessed: 26-Mar-2020]

[21] D. Fonseca Escudero, E. Redondo Domínguez, and F. Valls Dalmau, "Motivación y mejora académica utilizando realidad aumentada para el estudio de modelos tridimensionales arquitectónicos," vol. 17, no. 1, pp. 45-64, 2016.

[22] Ajuntament de Barcelona, "El espacio de encuentro con la gestión de la ciudad de Barcelona.," 2019. [Online]. Available: https://ajuntament.barcelona.cat/es. [Accessed: 2019]

[23] elPeriodico, "Barcelona apuesta por las TIC para impulsar turismo personalizado de calidad," 2013 [Online]. Available: https://www.elperiodico.com/es/barcelona/20130521/barcelona-apuesta-por-las-tic-para-impulsarturismo-personalizado-de-calidad-2396086. [Accessed: 2019]

[24] ESMARTCITY, "Una plataforma de gestión, turismo inteligente y realidad aumentada vertebran Toledo como smart city," 27-Sep-2019. [Online]. Available: https://www.esmartcity.es/2018/09/27/plataforma-gestion-turismo-inteligente-realidad-aumentada-vertebra-toledo-como-smart-city. [Accessed: 2019]

[25] I. M. Sánchez and A. A. N. Newball, "La ciudad escondida. Toledo, laboratorio de comunicaciónn transmedia," vol. 31, no. 1, pp. 806-827, 2015. 